\title{
Manifestações dermatológicas após cirurgia bariátrica: revisão sistemática de literatura
}

\author{
Andressa Christine Ferreira Silva*, Laura Moya Kazmarek, Elemir Macedo de Souza, Maria Letícia Cintra
}

\begin{abstract}
Resumo
É crescente o número de cirurgias bariátricas no mundo todo. Entre as principais complicações relatadas estão as deficiências nutricionais, que podem ocorrer a curto, médio ou longo prazo após a cirurgia. Muitas dessas carências manifestam-se primeiro por lesões dermatológicas, antes que agravos sistêmicos, que comprometem mais a saúde do paciente, ocorram. Nesse trabalho, buscamos identificar as principais manifestações dermatológicas secundárias à deficiência nutricional, pós cirurgia bariátrica, e as variáveis associadas, por meio de uma revisão sistemática da literatura. De 53 artigos encontrados, selecionamos 31 para testes estatísticos,somando 35 casos relatados. $O$ tipo de cirurgia mais frequente foi o de bypass gástrico em Y de Roux (RYGP), seguido da derivação biliopancreática. As deficiências mais identificadas foram as de zinco (60\%); vitamina A (40\%); vitamina D (28,57\%); cobre (25\%); vitamina B3 e vitamina E ( $11 \%$ cada); selênio e ferro (8,57\%); cálcio, vitamina $\mathrm{K}$ e vitamina $\mathrm{C}$ (2 a $5 \%$ cada). $28 \%$ das manifestações era de acrodermatite enteropática, que se associava, significantemente, ao tipo RYGP e à deficiência de zinco $(P<0,001)$, sem relação com o intervalo de tempo pós cirúrgico.
\end{abstract}

\section{Palavras-chave: Cirurgia Bariátrica, manifestações dermatológicas, deficiências nutricionais}

\section{Introdução}

A obesidade e sobrepeso estão entre as maiores preocupações de saúde pública mundial. Em 2016, 53\% da população adulta brasileira apresentava sobrepeso e $18 \%$ era obesa. Com o aumento da obesidade, cresce também o número de cirurgias bariátricas, consideradas um tratamento efetivo para a obesidade e comorbidades. Entre as principais complicações após cirurgia bariátrica estão as deficiências nutricionais, que podem ser decorrentes da grande perda de peso, má absorção de nutrientes e/ou mudança de hábitos. As carências mais comuns são as de vitamina B12, ferro e folato e, eventualmente, manifestam-se por meio de alterações dermatológicas, podendo evoluir para transtornos graves. Conhecê-las e identificá-las prontamente pode prevenir danos sistêmicos.

Nossos objetivos foram selecionar, da literatura, todos os artigos disponíveis sobre manifestações cutâneas de curto, médio e longo prazo, relacionadas a distúrbios nutricionais pós bariátrica, de qualquer categoria; identificar as manifestações mais frequentes e a quais carências nutricionais elas estão associadas.

\section{Resultados e Discussão}

Foram utilizadas as diretrizes básicas da recomendação PRISMA (Preferred Reporting Items for Systematic Review and Meta-Analysis Protocols). A pesquisa foi feita nos portais de pesquisa em saúde e bases de dados de periódicos biomédicos nacionais e internacionais (PubMed, Portal Regional da Biblioteca Virtual em Saúde (BVS), Scopus, EMBASE, Web of Science e Scielo), sem limitação de data de publicação. Os seguintes descritores foram utilizados para a pesquisa, seguindo a metodologia ideal em cada base de dados/portal de pesquisa: "bariatric surgery", "skin", "skin disease", "skin manifestation", "deficiency disease", "malnutrition". Foi realizada análise exploratória de dados pelas medidas - resumo (média, desvio padrão, mínimo, mediana, máximo, frequência e porcentagem). Para avaliar a associação entre as variáveis, foi realizada metanálise para dados individuais (IPD meta-analysis) pelos modelos de Regressão Logística com efeitos mistos, pelo método de Laplace. O nível de significância adotado foi de $5 \%$.

Obtivemos 53 artigos, sendo 22 artigos de revisão de literatura, de discussão do tema ou de pesquisas sobre manifestações dermatológicas específicas e 31 artigos relatando manifestações dermatológicas após cirurgia bariátrica, somando 35 artigos. A idade média dos pacientes era de 44 anos e o tempo médio decorrido entre a cirurgia a manifestação dermatológica foi de 5 anos. Nestes pacientes, o tipo de cirurgia mais frequente foi o bypass gástrico em $Y$ de Roux (68\%), seguido da derivação biliopancreática (14,29\%) e vários outros tipos. Dentre os artigos em que havia a informação, a adesão dos pacientes à suplementação nutricional pós-cirúrgica, apenas $50 \%$ deles aderiram. As deficiências mais identificadas foram as de zinco (60\%); vitamina A (40\%); vitamina $D(28 \%)$; cobre (25\%); vitamina $B 3$ e vitamina $E$ ( $11 \%$ cada); selênio e ferro ( $8 \%$ ); cálcio, vitamina $\mathrm{K}$ e vitamina C ( 2 a $5 \%$ cada). Dentre as manifestações, $28 \%$ era de acrodermatite enteropática, que se associou, significantemente, com o tipo RYGP $(P<0.001)$ e deficiência de zinco $(P<0,001)$, sem relação com 0 intervalo de tempo pós-cirúrgico.

\section{Conclusões}

Encontramos associação significante entre a acrodermatite enteropática, a deficiência de zinco e a técnica do bypass gástrico em $Y$ de Roux (RYGP). O RYGP foi a cirurgia bariátrica mais frequente nesta amostra, concordando com os dados que indicam que esse é o tipo de cirurgia mais realizado. Considerada a frequência com que as cirurgias bariátricas vêm sendo indicadas, poucos artigos foram encontrados nesta revisão. Ainda realizaremos a discussão integrando os outros 22 artigos levantados em nossa revisão.

\section{Agradecimentos}

Conselho Nacional de Desenvolvimento Científico e Tecnológico (CNPq).

Slater GH, Ren CJ, Siegel N, Williams T, Barr D, Wolfe B, et al. Serum fatsoluble vitamin deficiency and abnormal calcium metabolism after malabsorptive bariatric surgery. J Gastrointest Surg. 2004;8(1):48-55; discussion 4-5.

Swartz MH. Textbook of Physical Diagnosis: History and Examination: Elsevier Health Sciences; 2014. 